\title{
The Effect of Tax Avoidance on Firm Value-From the Perspective of Institutional Investor
}

\author{
Liu Xin-hua ${ }^{1, a}$ Cui Qian ${ }^{2, b}$ and Fu Meng-ting ${ }^{1, c}$ \\ ${ }^{1}$ School of Donlinks Economics and Management, University of Science and Technology Beijing, \\ 100083 China \\ ${ }^{2}$ Financial Department, Chinese Academy of Geological Sciences, 100037 China \\ aliuxh@management.ustb.edu.cn, bcuiqian114@126.com, chero569@163.com
}

\begin{abstract}
Though tax avoidance can reduce the expense of income tax and decrease the effective tax rate, it may not necessarily increase the firm value. This article shows that due to the agency problems, tax avoidance may become the shield for managers' rent-seeking behaviors, thus making the costs of tax avoidance exceed the gains it brings, which eventually leads to the negative effect on firm value. The interaction of institutional investors and tax avoidance can have a positive effect on firm value, which implies that institutional investors will restrain tax avoidance activities in order to stop the managers from expropriating the interests of the owners, play the role of corporate governance effectively, making tax avoidance activities increase the firm value indeed.
\end{abstract}

Keywords: tax avoidance, firm value, institutional investors.

\section{税收规避程度对公司价值的影响研究一一基于机构投资者的视角 \\ 刘欣华 ${ }^{1, a}$, 崔倩 ${ }^{2, b}$, 傅梦婷 ${ }^{1, c}$ \\ ${ }^{1}$ 北京科技大学东凌经济管理学院, 北京, 中国 \\ 2中国地质科学院财务部, 北京, 中国 \\ aliuxh@management.ustb.edu.cn, bcuiqian114@126.com, chero569@163.com}

中文摘要. 企业从事税收规避活动可以减 少其纳税支出, 降低其实际税负, 却并不一 定能够带来公司价值的提高。本文研究发 现, 企业的税收规避程度与其公司价值间存 在显著的负相关关系, 说明由于代理问题的 存在, 税收规避活动带来的成本超过了其带 来的收益, 最终使公司价值受损, 而企业拥 有机构投资者持股能够对其管理层借以牟 取私利的税收规避活动起到一定的抑制作 用, 使税收规避活动能够从企业所有者的利 益出发, 真正为企业带来公司价值的提高。
关键词：税收规避；公司价值；机构投资者

\section{1. 引言}

为了增加税后每股收益以及所有者可 使用的现金，企业会从事税收规避活动。而 税收规避活动却并不一定能够增加企业的 价值, 这主要是由于税收规避行为导致的代 理成本的存在, 税收规避活动很可能成为管 理层机会主义及其寻租行为的挡箭牌。国外 学者针对企业税收规避程度与其公司价值 间关系进行实证研究后普遍认为, 企业的税 
收规避程度越高, 其公司价值反而越低, 而 国内学者在进行相关实证研究后得出了不 同的结论。此外, 国外学者经研究后普遍发 现机构投资者能够较好地抑制管理层进行 税收规避时的寻租行为, 使税收规避活动真 正为企业带来增值, 但国内学者在研究税收 规避时却较少考虑机构投资者这一影响因 素。因此, 本文从机构投资者的视角展开对 税收规避程度和公司价值关系的研究, 有助 于明确企业的税收规避活动对其公司价值 的实际影响, 也有助于研究机构投资者的公 司治理作用。

\section{2. 理论分析与研究假设}

\section{1 税收规避与公司价值}

企业进行税收规避活动的后果可能是 正面的, 例如减少了所得税费用支出, 从 而增加了企业的现金流和所有者的财富; 有助于降低企业对债务融资的依赖度, 减 少了债务违约风险, 从而降低了债务融资 成本等等; 其后果也可能是负面的, 即税 收规避活动在为企业带来收益的同时, 带 来了更多的成本, 例如企业可能因其激进 的税收规避政策而引起税务机关的注意, 导致税务机关对其进行稽查, 由此可能会 被迫支付额外的税款或罚金（盖地、胡国 强，2012）。

由于代理问题的存在, 管理层在从事 税收规避活动的同时往往伴随着一些机会 主义行为的发生, 以增加其自身利益, 从 而在某种程度上侵占了属于企业所有者的 利益。税收规避往往非常复杂, 例如转移 收入和负债、安排复杂的关联交易等等, 这些活动难以被审计师和税务机关发现。 因此, 管理层借助各种税收规避行为进行 利益侵占也变得更为隐蔽。税收规避行为 越多, 寻租的操作空间就越大, 管理层更 容易牟取私利, 寻租反过来又继续推动管 理层实施税收规避的冲动。此外, 管理层 可能借助税收规避行为隐藏企业的负面消 息, 这也增加了企业股票未来崩盘的风险
(江轩宇, 2013)。企业实施税收规避行为 时, 最终公司价值的变化取决于这一行为 带来的税收节约效益和隐藏在背后的利益 侵占成本、被税务机关实施稽查的税务惩 罚成本等一系列因素的权衡。

本文认为, 由于我国企业的公司治理程 度仍有待完善, 企业普遍面临着较为严重的 代理问题, 因而管理层从事过多的税收规避 活动反而会损害企业的价值, 据此提出假设 1: 企业的税收规避程度越大, 其公司价值 越低。

\section{2 机构投资者与税收规避}

国内外学者以往的研究结果表明机构 投资者在现代企业的公司治理中发挥着重 要的作用, 原因在于机构投资者作为企业 的所有者, 为了维护自身利益, 有动力对 企业管理层的各项决策及行为进行监督与 约束, 从而抑制管理层的机会主义行为, 缓解企业的代理问题, 并且机构投资者具 有信息、资源、专业化团队等优势，因而 更有能力参与到企业的公司治理中, 利用 其自身优势改善企业在运营管理中存在的 各种问题（李维安、李滨, 2008)。税收规 避活动可能会为管理层进行寻租提供机 会, 使得企业的代理成本有所增加, 因此 会引起机构投资者的关注。本文认为机构 投资者能够在一定程度上抑制管理层借以 牟取自身私利的税收规避活动, 据此提出 假设 $2 \mathrm{a}$ ：企业的机构投资者整体持股比例 越高, 其税收规避程度越低。

不同类型的机构投资者发挥公司治理 作用的程度可能存在着差异。如果机构投资 者与被投资企业有着较为密切的业务关系， 为维护与被投资企业的业务往来及未来合 作的机会, 往往会选择顺从企业管理层的意 图, 其参与公司治理的程度可能会有所减 弱。而那些与被投资企业只有投资关系机构 投资者, 由于其相对独立性, 在参与被投资 企业的公司治理时往往不受企业管理层的 影响, 不会因利益冲突而轻易顺从管理层的 意图, 可以更加积极地发挥治理作用 
(Brickley, Lease, \& Smith Jr, 1988)。基金公 司受到证监会的严格监管, 透明度较高, 很 少会与被投资企业联手炒作, 因此本文认为 基金类型的机构投资者能够更加积极地发 挥公司治理作用, 据此提出假设 $2 \mathrm{~b}$ : 企业的 基金持股比例越高，其税收规避程度越低， 且基金持股比例对税收规避程度的抑制作 用强于机构投资者整体持股比例的作用。

\section{3 机构投资者持股比例和税收规避程度 的交互项与公司价值}

本文认为公司治理情况较好的企业在 进行税收规避时能真正从企业所有者的利 益出发, 遏制其自身借此进行寻租及利益 侵占行为的发生, 其税收规避活动才能真 正带来公司价值的提高。由于机构投资者 有充分的动机参与被投资企业的公司治 理, 能够在一定程度上发挥有效的监管作 用, 可以抑制管理层借助税收规避活动进 行利益侵占的现象 (穆林娟、张红, 2008), 因而对机构投资者整体持股比例较 高的企业, 税收规避活动能够真正提高其 公司价值, 据此提出假设 $3 \mathrm{a}$ : 企业的机构 投资者整体持股比例与税收规避程度的交 互项越大，其公司价值越高。

单独对基金这一类型的投资机构进行 考察时, 也可以得出类似结论, 据此提出假 设 $3 \mathrm{~b}$ : 企业的基金持股比例与税收规避程度 的交互项越大，其公司价值越高。

\section{3. 研究设计}

\section{1 变量设计}

（1）公司价值

本文采用企业年末的 Tobin's Q 值来衡 量其公司价值，计算方法如下：
商、合格的境外机构投资者（QFII）、保险 公司、社保基金、企业年金、信托公司、 财务公司以及其他机构投资者。本文对机 构投资者整体持股比例 Ins_share 的定义: 在某一企业中以上类型的投资机构所持有 的 $\mathrm{A}$ 股数量之和占被投资企业发行的 $\mathrm{A}$ 股 总数的比例。

本文还设置了基金持股比例 $\mathrm{Fd}$ _share 这一变量, 代表基金持有的 $\mathrm{A}$ 股数量占被 投资企业发行的 A 股总数的比例。

（3）税收规避程度

本文采用账面税收差异残差来衡量企 业的税收规避程度，借鉴 Desai and Dharmapala（2006）的方法具体计算方法如 下:

$B T D_{i, t}=\frac{\text { 利润总额 }-(\text { 所得税费用-递延所得税费用 }) / \text { 名义税率 }}{\text { 总资产 }}$

$T A_{i, t}=\frac{\text { 净利润-经营活动产生的现金流量净额 }}{\text { 总资产 }}$

令 $B T D_{i, t}=\alpha_{1} T A_{i, t}+\mu_{i}+\varepsilon_{i, t}$ 进行回归, 得到 的残差 $A B T D_{i, t}=\mu_{i}+\varepsilon_{i, t}$ 用以衡量企业的税收 规避程度。

（4）其他控制变量

在考察税收规避程度对公司价值的影 响、机构投资者持股与税收规避程度的交 互项对公司价值的影响时，本文设置了如 下控制变量:

(1)企业规模 Size，取总资产的自然对 数;

(2)财务杜杆 Lev，即企业总负债占总 Tobin's $Q_{i, t}=\frac{\text { 每股市价 } \times \text { 流通股股数 }+ \text { 每股净资产 } \times \text { 非流通股股数 }+ \text { 负债账面深值 }}{\text { 总资产 }^{\prime}}$

（2）机构投资者持股比例

我国机构投资者主要包括基金、券 占总资产的比重;

(4)股权集中度，包括企业第一大股东 的持股比例 Top1、第二至第五大股东的持 股比例之和 Top5; 
(5)成长性 Growth, 取企业当年营业收 入相较于去年的增长率;

(6)独董比例 Indep, 即企业的独立董事 人数占董事会总人数的比重;

(7)所有权性质 State, 若企业的实际控 制人为国有性质，则取值为 1 , 否则为 0 。

在考察机构投资者持股对税收规避程 度的影响时, 本文设置了如下控制变量:

(1)企业规模 Size, 取总资产的自然对 数;

(2)财务杜杆 Lev, 即企业总负债占总资 产的比重;

(3)总资产报酬率 $R O A$, 即企业净利润 占总资产的比重;

(4)固定资产密集度 $P P E$, 即企业固定 资产占总资产的比重;

(5)无形资产密集度 INTANG, 即企业 无形资产占总资产的比重;

66审计师类型 Big4, 若审计师为四大 会计师事务所, 则取值为 1 , 否则为 0 ;

(7)所有权性质 State, 若企业的实际控 制人为国有性质, 则取值为 1 , 否则为 0 。

此外, 本文增加年度Year及行业Industry 两类变量, 以控制样本数据的年度及行业效 应。其中, 以2010年为基准年份, 对 2011 年、2012年分别设置虚拟变量; 以综合业为 基准行业, 对其余行业分别设置虚拟变量。

\section{2 模型建立}

为检验假设 1 , 考察税收规避程度对 公司价值的影响, 本文设置了如下回归模 型:

$$
\begin{aligned}
& \text { Tobin's } Q_{i, t}={ }_{0}+{ }_{1} A B T D_{i, t}+{ }_{2} S_{i z e}+{ }_{i, t}{ }{ } e v_{i, t} \\
& +{ }_{4} R O A_{i, t}+{ }_{5} \text {Top }_{i, t}+{ }_{6} \text { Top } 5_{i, t}+{ }_{7} \text { Growth }_{i, t} \\
& +{ }_{8} \text { Indep }_{i, t}+{ }_{9} \text { State }_{i, t}+{ }_{10} \text { Year }+{ }_{11} \text { Industry }{ }_{i, t}
\end{aligned}
$$

为检验假设 $2 \mathrm{a}$ 、假设 $2 \mathrm{~b}$, 分别考察机 构投资者整体持股比例、基金持股比例对 税收规避程度的影响, 本文设置了如下两 个回归模型:

$$
\begin{aligned}
& A B T D_{i, t}={ }_{0}+{ }_{1} \text { Ins_share }{ }_{i, t}+{ }_{2} \text { Size }_{i, t}+{ }_{3} \text { Lev }_{i, t} \\
& +{ }_{4} R O A_{i, t}+{ }_{5} P P E_{i, t}+{ }_{6} I N T A N G_{i, t}+{ }_{7} B_{i g} 4_{i, t} \\
& +{ }_{8} \text { State }_{i, t}+{ }_{9} \text { Year }+{ }_{10} \text { Industry }+{ }_{i, t} \\
& A B T D_{i, t}={ }_{0}+{ }_{1} F_{d} \text { share }_{i, t}+{ }_{2} \text { Size }_{i, t}+{ }_{3} \text { Lev }_{i, t} \\
& +{ }_{4} R O A_{i, t}+{ }_{5} P P E_{i, t}+{ }_{6} I N T A N G_{i, t}+{ }_{7} \text { Big }_{i, t} \\
& +{ }_{8} \text { State }_{i, t}+{ }_{9} \text { Year }+{ }_{10} \text { Industry }+{ }_{i, t}
\end{aligned}
$$

为检验假设 $3 \mathrm{a} 、$ 假设 $3 \mathrm{~b}$, 分别考察机 构投资者整体持股比例与税收规避程度的 交互作用、基金持股比例与税收规避程度 的交互作用对公司价值的影响, 本文设置 了如下两个回归模型:

$$
\begin{aligned}
& \text { To b isn } Q_{4, t}={ }_{0}+{ }_{1} A B T_{i, l} D+{ }_{2} I n \underline{s} s h a r_{t, t} \\
& { }_{3} A B T_{i, D^{*}} I n \underline{s} s h a r_{t,}{ }_{4} S i z_{i, t} e+{ }_{5} L e_{i, t} \\
& +{ }_{6} R O A+{ }_{7} T o p_{i, t}+{ }_{8} T o \tilde{p}_{i, t}+{ }_{9} G r o w_{i, t} t h
\end{aligned}
$$

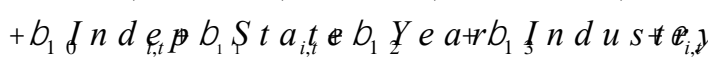

$$
\begin{aligned}
& \text { Tobisn } Q_{t, t}={ }_{0}+{ }_{1} A B T P t_{t, 1}{ }_{2} F d_{-} s h a \gamma_{, t} \text { t } \\
& { }_{3} A B T D_{i, D^{*}} F d_{-} s h a r_{, t} \notin{ }_{4} S i z_{i,},+{ }_{5} L e_{i, t} \\
& +{ }_{6} R O A,+{ }_{7} T o p_{i, t}+{ }_{8} T o p_{i, t}+{ }_{9} G r o w_{i}, t h
\end{aligned}
$$

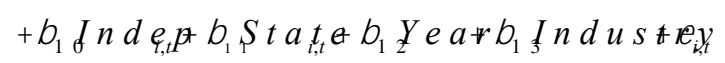

\section{3 样本选择}

本文以2010-2012年沪深 A 股上市公 司为样本, 并按如下标准进行数据篮选: (1) 剔除金融行业的样本; (2) 剔除利润总额 为负和净利润为负的样本; (3) 剔除其他 相关数据有缺失的样本。最终得到的 3649 个样本。研究所需的数据来源于RESSET数 据库, 并经过计算及手工䇻选得到。

表1 样本分布情况

\begin{tabular}{|c|c|c|c|}
\hline & 全样本组 & $\begin{array}{c}\text { 有机构投资者持 } \\
\text { 股样本组 }\end{array}$ & 有基金持股样本组 \\
\hline 2010年 & 1187 & 1139 & 972 \\
\hline 2011年 & 1200 & 1178 & 1056 \\
\hline 2012年 & 1262 & 1242 & 1073 \\
\hline 合计 & 3649 & 3559 & 3101 \\
\hline
\end{tabular}




\section{4. 实证结果}

\section{1 变量描述性统计}

从表2可以看出, 我国主板A股上市企 业间的公司价值存在较大差异, 企业Tobin, $s Q$ 最小值为 0.1825 , 最大值为 8.2285 , 标准 差较大。在 3649 个研究样本中, 有 3559 个研 究样本的机构投资者持股比例大于 0 , 说明 目前我国企业普遍引入了机构投资者持股, 且整体持股比例最高达到了 $74.89 \%$, 因此 研究机构投资者作为企业的外部所有者是 否发挥有效的公司治理作用非常必要。在拥 有机构投资者持股的3559个研究样本中, 有 3101 个研究样本拥有基金持股, 比重达 $87.13 \%$, 且比例最高达到了 $35.62 \%$, 因此 对基金类型的投资机构者单独进行考察有 助于了解不同类型的机构投资者参与公司 治理程度的差异。衡量企业税收规避程度的 $A B T D$ 的最小值为 -0.0954 , 最大值为 0.1205 , 说明有些企业选择了较为激进的税收规避 政策, 有些企业则并未进行税收规避活动, 可能考虑了由此带来的财务报告成本, 例如 担心较低的税前利润会引起债权人的担忧 而使企业的举债能力受到影响、会引起股价 的下降而降低企业在股票市场的融资能力, 甚至会引起税务机关的关注而使企业被迫 接受税务稽查等等, 反而选择了减小其账面 税收差异(盖地、胡国强, 2013)。

表2 变量描述性统计

\begin{tabular}{|c|c|c|c|c|c|}
\hline 变量 & $\mathbf{N}$ & 最小值 & 最大值 & 均值 & 标准差 \\
\hline Tobin's $Q$ & 3649 & 0.1825 & 8.2285 & 1.7960 & 1.5033 \\
\hline Ins_share & 3649 & 0.0000 & 0.7489 & 0.1594 & 0.1743 \\
\hline Fd_share & 3649 & 0.0000 & 0.3562 & 0.0481 & 0.0729 \\
\hline ABTD & 3649 & -0.0954 & 0.1205 & 0.0000 & 0.0286 \\
\hline Size & 3649 & 19.5033 & 25.9226 & 21.9404 & 1.2517 \\
\hline Lev & 3649 & 0.0459 & 0.8832 & 0.4553 & 0.2126 \\
\hline ROA & 3649 & 0.0010 & 0.2061 & 0.0521 & 0.0413 \\
\hline Top1 & 3649 & 0.0896 & 0.7843 & 0.3756 & 0.1588 \\
\hline Top5 & 3649 & 0.1738 & 0.8890 & 0.5417 & 0.1681 \\
\hline Growth & 3649 & -0.4912 & 1.9329 & 0.2091 & 0.3335 \\
\hline Indep & 3649 & 0.1500 & 0.6000 & 0.3518 & 0.0865 \\
\hline
\end{tabular}

\begin{tabular}{|c|c|c|c|c|c|}
\hline State & 3649 & 0 & 1 & 0.5100 & 0.5000 \\
\hline PPE & 3649 & 0.0017 & 0.7441 & 0.2329 & 0.1744 \\
\hline INTANG & 3649 & 0.0000 & 0.3441 & 0.0463 & 0.0547 \\
\hline Big4 & 3649 & 0 & 1 & 0.0700 & 0.2490 \\
\hline
\end{tabular}

\section{2 多元回归分析}

从表 3 对模型 1 的回归结果可以看出, 在 控制了其他因素的影响后, $A B T D$ 的回归系数 在 $1 \%$ 的水平上显著为负, 即企业的税收规避 程度越高, 其公司价值越低, 验证了假设 1 , 说明进行税收规避活动虽然可以节约企业 的所得税支出, 降低企业的实际税负, 但由 于代理问题的存在, 管理层会借助税收规避 活动进行寻租, 为了满足自身私利而损害了 企业的整体价值。

从表 4 对模型 2 的回归结果可以看出, Ins_share的回归系数为负, 但不显著, 说 明机构投资者整体持股虽然能对企业的税 收规避活动起到一定的抑制作用, 但效果并 不明显。从对模型 3 的回归结果可以看出, Fd_share的回归系数显著为负, 验证了假设 $2 \mathrm{~b}$, 说明企业拥有基金持股能够对其税收规 避活动起到较好的抑制作用。这也验证了前 文中的分析，即某些类型的投资机构与被投 资企业有着较为密切的业务关系, 担心违背 管理层的意图会丧失掉与被投资企业的业 务往来及未来合作的机会, 因此参与公司治 理的程度会有所减弱, 对管理层从事税收规 避活动的监管作用也较弱。而基金类型的投 资机构由于与被投资企业没有其他业务关 系, 能更加积极地发挥公司治理的作用, 从 而有效地抑制了管理层会损害企业整体价 值的税收规避行为。

从表 3 对模型 4 的回归结果可以看出, $A B T D \times I n s$ share的回归系数均显著为正, 验证了假设 $3 a$, 说明机构投资者整体持股可 以抑制管理层在从事税收规避活动时寻租 现象的发生, 从而使税收规避活动能够真正 提高企业的公司价值。从对模型 5 的回归结 果中可以看出, $A B T D \times F d$ share的回归系数 均显著为正, 验证了假设 $3 \mathrm{~b}$, 说明单独考虑 基金这一类型的投资机构也可以有效抑制 管理层借助税收规避活动进行利益侵占的 行为, 从而提高企业的公司价值。 


\section{3 稳健性检验}

为保证研究结果的稳健性, 分别使用账 面税收差异 $B T D$ 、名义税率与实际税率差额 Rate_diff这两项指标衡量企业的税收规避 程度, 将样本数据带入 5 个模型中进行回归 分析。到的回归结果基本与以 $A B T D$ 来衡量 税收规避程度时得到的结果相同, 进一步验 证了本文提出的假设。

表 3 模型 1 、模型 4 及模型 5 的回归结果

\begin{tabular}{|c|c|c|c|}
\hline & 模型1 & 模型4 & 模型5 \\
\hline 常量 & $\begin{array}{c}13.085^{* * *} \\
(37.820)\end{array}$ & $\begin{array}{c}13.194 * * * \\
(38.225)\end{array}$ & $\begin{array}{c}14.209 * * * \\
(41.143)\end{array}$ \\
\hline$A B T D$ & $\begin{array}{c}-2.718 * * * \\
(-4.511)\end{array}$ & $\begin{array}{c}-4.961 * * * \\
(-5.953)\end{array}$ & $\begin{array}{c}-2.906^{* * * *} \\
(-3.979)\end{array}$ \\
\hline Ins_share & & $\begin{array}{c}0.380 * * * \\
(3.861)\end{array}$ & \\
\hline$A B T D \times$ Ins_share & & $\begin{array}{c}12.321 * * * \\
(3.992)\end{array}$ & \\
\hline Fd_share & & & $\begin{array}{c}3.621 \text { *** } \\
(14.307)\end{array}$ \\
\hline$A B T D \times F d$ _share & & & $\begin{array}{c}13.020^{* * *} \\
(2.113)\end{array}$ \\
\hline Size & $\begin{array}{l}-0.518 * * * \\
(-31.121)\end{array}$ & $\begin{array}{c}-0.525 * * * \\
(-31.560)\end{array}$ & $\begin{array}{c}-0.576^{* * *} \\
(-34.542)\end{array}$ \\
\hline Lev & $\begin{array}{c}-1.126 * * * \\
(-10.976)\end{array}$ & $\begin{array}{c}-1.132 * * * \\
(-11.058)\end{array}$ & $\begin{array}{c}-1.180 * * * \\
(-11.809)\end{array}$ \\
\hline$R O A$ & $\begin{array}{c}13.059 * * * \\
(28.034)\end{array}$ & $\begin{array}{c}12.814 * * * \\
(27.310)\end{array}$ & $\begin{array}{c}10.374 * * * \\
(21.119)\end{array}$ \\
\hline Top1 & $\begin{array}{c}0.205 \\
(1.268)\end{array}$ & $\begin{array}{l}0.318^{*} \\
(1.945)\end{array}$ & $\begin{array}{c}0.462 * * * \\
(2.918)\end{array}$ \\
\hline Top5 & $\begin{array}{c}0.072 \\
(0.465)\end{array}$ & $\begin{array}{c}-0.019 \\
(-0.122)\end{array}$ & $\begin{array}{c}0.207 \\
(1.373)\end{array}$ \\
\hline Growth & $\begin{array}{c}0.354 * * * \\
(6.713)\end{array}$ & $\begin{array}{c}0.352 * * * \\
(6.699)\end{array}$ & $\begin{array}{c}0.342 * * * \\
(6.657)\end{array}$ \\
\hline Indep & $\begin{array}{c}0.486^{* * *} \\
(2.491)\end{array}$ & $\begin{array}{c}0.479 * * \\
(2.465)\end{array}$ & $\begin{array}{l}0.321^{*} \\
(1.690)\end{array}$ \\
\hline State & $\begin{array}{c}0.037 \\
(0.988)\end{array}$ & $\begin{array}{c}0.034 \\
(0.919)\end{array}$ & $\begin{array}{c}0.036 \\
(0.987)\end{array}$ \\
\hline Year & 已控制 & 已控制 & 已控制 \\
\hline Industry & 已控制 & 已控制 & 已控制 \\
\hline $\mathrm{N}$ & 3649 & 3649 & 3649 \\
\hline Adjusted $\mathrm{R}^{2}$ & 0.558 & 0.561 & 0.582 \\
\hline F & $171.441 * * *$ & $161.994 * * *$ & 176.032 *** \\
\hline
\end{tabular}

注: 括号外的数值为回归系数, 括号内的数值为 $\mathrm{t}$ 值（下同）
表4 模型2、模型3的回归结果

\begin{tabular}{|c|c|c|}
\hline & 模型2 & 模型3 \\
\hline 常量 & $\begin{array}{c}0.049 * * * \\
(4.905)\end{array}$ & $\begin{array}{c}0.043 * * * \\
(4.193)\end{array}$ \\
\hline Ins_share & $\begin{array}{c}-0.004 \\
(-1.358)\end{array}$ & \\
\hline$F d \_$share & & $\begin{array}{c}-0.026 * * * \\
(-3.791)\end{array}$ \\
\hline Size & $\begin{array}{c}-0.003 * * * * \\
(-5.424)\end{array}$ & $\begin{array}{c}-0.002 * * * * \\
(-4.727)\end{array}$ \\
\hline Lev & $\begin{array}{c}-0.004 \\
(-1.626)\end{array}$ & $\begin{array}{c}-0.004 \\
(-1.400)\end{array}$ \\
\hline$R O A$ & $\begin{array}{c}0.157 * * * \\
(12.589)\end{array}$ & $\begin{array}{l}0.172 * * * \\
(13.074)\end{array}$ \\
\hline$P P E$ & $\begin{array}{c}0.020 * * * \\
(7.586)\end{array}$ & $\begin{array}{c}0.020 * * * \\
(7.417)\end{array}$ \\
\hline INTANG & $\begin{array}{l}-0.016^{*} \\
(-1.853)\end{array}$ & $\begin{array}{l}-0.015^{*} \\
(-1.841)\end{array}$ \\
\hline Big4 & $\begin{array}{c}0.005 * * * \\
(2.646)\end{array}$ & $\begin{array}{l}0.005^{* * *} \\
(2.546)\end{array}$ \\
\hline State & $\begin{array}{c}0.002 * * \\
(2.094) \\
\end{array}$ & $\begin{array}{l}0.002^{* *} \\
(2.060) \\
\end{array}$ \\
\hline Year & 已控制 & 已控制 \\
\hline Industry & 已控制 & 已控制 \\
\hline $\mathrm{N}$ & 3649 & 3649 \\
\hline Adjusted $\mathrm{R}^{2}$ & 0.080 & 0.083 \\
\hline $\mathrm{F}$ & $13.221 * * *$ & $13.748 * * *$ \\
\hline
\end{tabular}

\section{5. 结束语}

本文考察企业税收规避程度对其公司 价值的影响，并纳入机构投资者这一外部 监督机制的治理作用，研究企业的机构投 资者持股对其税收规避程度的影响, 以及 机构投资者持股与税收规避程度的交互作 用对公司价值的影响, 得出了以下结论:

（1）企业的税收规避程度越大，其公司价 值反而越低，说明企业管理层进行税收规 避时存在机会主义行为, 通过安排复杂的 税收规避活动进行利益侵占, 使税收规避 活动带来的成本超过了其带来的收益，从 而损害了企业的价值。（2）投资机构者发 挥了较为有效的监督治理作用, 能够对企 业管理层借以牟取私利的税收规避活动起 到一定的抑制作用。基金持股比例对税收 
规避程度的抑制作用强于机构投资者整体 持股比例的作用。（3）对于机构投资者整 体持股比例、基金持股比例较高的企业， 由于机构投资者能够发挥较好的公司治理 作用, 抑制了企业管理层进行税收规避活 动时的机会主义行为, 税收规避活动能够 真正为企业带来公司价值的增加。

本文的研究可以为企业制定税收规避 政策、机构投资者参与被投资企业的公司治 理等提供参考。对企业所有者而言, 需要在 税收规避活动的收益与成本间进行权衡, 慎 重地考虑是否仍要采取较为激进的税收规 避政策, 并对其管理层安排的税收规避活动 实施有效的监督, 杜绝管理层借此进行利益 侵占的现象的发生, 使税收规避活动能够真 正为所有者带来价值。机构投资者应当充分 利用其优势, 积极发挥对被投资企业的治理 作用, 对管理层的决策及行为进行监督, 抑 制管理层进行税收规避时的机会主义行为。 税务机关要完善企业所得税征收管理等相 关制度的建设, 提高对企业税收规避活动中 的不合理现象的稽查力度, 对企业进行鞭 策, 从而保障我国广大的中小投资者的切身 利益, 促进资本市场更加平稳、有序地发展。

\section{致谢}

本文是 “北京科技大学研究型教学示 范课程建设项目” ( KC2013YJX25)和 “北 京科技大学基本科研业务费项目”

(FRF-TP-14-054A2) 的阶段性成果之一。

\section{References}

[1] GAI Di, HU Guo-qiang, Research on Balancing Tax Avoidance and Cost of Financial Report-Evidence from Chinese Reform of Income Tax in 2008, Accounting Research, vol.3, pp. 20-25, 2012.
[2] JIANG Xuan-yu, Tax Enforcement, Tax Aggressiveness and Stock Price Crash Risk, Nankai Business Review, vol.5, pp. 152-160, 2013.

[3] LI Huai-an, LI Bin, An Empirical Study on the Effect of Institutional Investors Participating in Corporate Governance: Based on the Data of 2004-2006 CCGI ${ }^{\mathrm{NK}}$, Nankai Business Review, vol.1, pp. 4-14, 2008.

[4] Brickley, J. A., Lease, R. C., \& Smith Jr, C. W., Ownership structure and voting on antitakeover amendments, Journal of financial economics, vol. 20, pp. 267-291, 1988.

[5] MU Lin-juan, ZHANG Hang, Study on Relationship between Shares-proportion of Institutional Investors and Corporation Performance of Listed Companies-Based on Empirical Data of Chinese Listed Companies, Journal of Beijing Technology and Business University, vol. 4, pp. 76-82, 2008.

[6] M. Ben-Daya, M. Darwis, and K. Ertogral, The joint economic lot sizing problem: Review and extensions, European Journal of Operational Research, vol. 185, pp. 726-742, 2008.

[7] Desai, M. A., \& Dharmapala, D., Corporate tax avoidance and high-powered incentives, Journal of Financial Economics, vol. 79, pp. 145-179, 2006.

[8] SUN Gang, Taxation Monitoring, Corporate Tax Avoidance and Cost of Debt Financing, Journal of Shanxi Finance and Economics University, vol. 3, pp. 78-89, 2013. 